\title{
Health of Newly Arrived Immigrants in Canada and the United States: Differential Selection on Health
}

Yao Lu, Department of Sociology, Columbia University, New York, NY 10027, USA

Neeraj Kaushal, School of Social Work, Columbia University, New York, NY 10027, USA

Nicole Denier, Department of Sociology, McGill University, Montreal, Canada, and

Colby College, Waterville, Maine 04901, USA

Julia Shu-Huah Wang, School of Social Work, Hong Kong University, Hong Kong

\section{Full citation:}

Lu, Yao, Neeraj Kaushal, Nicole Denier, and Julia Shu-Huah Wang. 2017. "Health of Newly Arrived Immigrants in Canada and the United States: Differential Selection on Health." Health \& Place 48:1-10.

\section{Corresponding author:}

Yao Lu

Department of Sociology

Columbia University

New York, NY 10027, USA

yao.1u@,columbia.edu

\section{Acknowledgement:}

The authors are grateful for support by the National Science Foundation (SES 1226546), the Russell Sage Foundation, and the Columbia Population Research Center with funding from the Eunice Kennedy Shriver National Institute of Child Health and Human Development (R24 HD058486). Data access was provided by Statistics Canada. The analysis presented in this paper was conducted at the Quebec Interuniversity Centre for Social Statistics, which is part of the Canadian Research Data Centre Network (CRDCN). 


\title{
Health of Newly Arrived Immigrants in Canada and the United States: Differential Selection on Health
}

\author{
Abstract \\ Canada and the U.S. are two major immigrant-receiving countries characterized by different \\ immigration policies and health care systems. The present study examines whether immigrant \\ health selection, or the "healthy immigrant effect", differs by destination and what factors may \\ account for differences in immigrant health selection. We use 12 years of U.S. National Health \\ Interview Survey and Canadian Community Health Survey data to compare the risks of \\ overweight/obesity and chronic health conditions among new immigrants in the two countries. \\ Results suggest a more positive health selection of immigrants to Canada than the U.S. \\ Specifically, newly arrived U.S. immigrants are more likely to be overweight or obese and have \\ serious chronic health conditions than their Canadian counterparts. The difference in \\ overweight/obesity was explained by differences in source regions and educational levels of \\ immigrants across the two countries. But this is not the case for serious chronic conditions. \\ These results suggest that immigration-related policies can potentially shape immigrant health \\ selection.
}

Key words: Immigration; Healthy immigrant effect; Selection; United States; Canada 


\section{Introduction}

Immigrants are a rapidly growing segment of the U.S. and Canadian populations. By $2010,12.9 \%$ of the U.S. and $20.6 \%$ of the Canadian population were foreign-born (Camarota, 2011; Statistics Canada 2013). Characteristics of immigrants upon arrival, including health, are crucial in shaping their subsequent well-being and incorporation in the destination society. Previous research documents that immigrants in both countries are positively selected on health such that they have better health than native populations upon arrival (Abraído-Lanza et al. 2005; Antecol and Bedard 2006; Lara et al. 2005; Palloni and Arias 2004; Kennedy et al. 2014; Akresh and Frank 2008; Nauman et al. 2015; McDonald and Kennedy 2004; Rubalcava et al., 2008; Siddiqi et al. 2013). An important yet underexplored question is whether the "healthy immigrant effect" varies across destinations characterized by different immigration policies and health care systems. Cross-national comparative research allows us to investigate this question.

We examine whether there are systematic differences in immigrant health selection in Canada and the U.S., by comparing the health of new immigrants in their first year of arrival. The US-Canada comparison is inspired by the similarities and differences between the two countries. Canada and the U.S. both have federal state structures and capitalist economic systems. They have also received large numbers of immigrants based on family ties, skills, economic contribution, and other channels. However, the relative magnitude of these immigration categories varies substantially (Department of Homeland Security 2012; Government of Canada 2012). Canada has instituted an explicit points-based immigration system since the 1960s that selects on human capital characteristics (Greenwood and McDowell 1991). The U.S., by contrast, has adopted an immigration system that primarily emphasizes family reunification. Primarily as a consequence of this difference, Canada draws a higher proportion of 
skilled immigrants than the U.S., even among immigrants from the same source country (Kaushal and $\mathrm{Lu}$ 2014). Other destination factors such as immigrant health screening policies and health care systems may also shape immigrant health selection. Both countries adopt health screening as a formal part of the immigration process, albeit with some differences in what constitute health grounds for rejection. As for the health care system, Canada has mostly universal health insurance, whereas the U.S. healthcare system has been largely based on private insurance.

Such contextual differences provide an interesting contrast to examine the relative health selection of immigrants. For example, although health is not explicitly assigned a point value in Canada's point system, insofar as the system positively selects on human capital and human capital is positively associated with health, relative health selection is likely to favor immigrants to Canada. Or, to the extent that destination welfare systems factor into immigrant decisionmaking, individuals with health impairments may find Canada's universal health care system more appealing than the U.S. private-based system.

We use comparable national data over the period of 2001-2012: the National Health Interview Survey (NHIS) in the U.S. and the Canadian Community Health Survey (CCHS). We study post-2000 immigration, a period during which over 15 million legal immigrants entered the two countries. We focus on very recent immigrants, defined as those who arrived within 1 year of the survey, because their health would best capture health status upon arrival (selection) and is least conflated with health assimilation or return migration. In addition, we compare immigrants in the two countries rather than with the respective native population in each country. The latter, albeit an important comparison in its own right, tends to obscure immigrant health selection with the general health profile of the native population. This could be especially problematic since 
Canadians are healthier than Americans in general (Lasser, Himmelstein, Woolhandler 2006;

O’Neill and O’Neil 2008).

\section{Background and Hypotheses}

\subsection{Immigrant Health Selection}

Studies of immigrant health, including those on immigrants to Canada and the U.S., commonly document a better health profile of immigrants than that of the native-born populations in host societies, even when they come from countries with a high rate of mortality and morbidity (Cunningham et al. 2008). Immigrants' health advantage is manifested in a wide range of health outcomes including mortality, chronic conditions such as hypertension and heart disease, mental health, and health risk behaviors such as smoking (Abraído-Lanza et al. 2005; Antecol and Bedard 2006; Lara et al. 2005; Palloni and Arias 2004; Kennedy et al. 2014; Akresh and Frank 2008; Nauman et al. 2015; McDonald and Kennedy 2004; Rubalcava et al., 2008; Siddiqi et al. 2013).

The primary explanation advanced for the "healthy migrant effect" is that immigration is a selective process. Because the process of migration and adjustment to a new environment is often arduous and stressful, a minimal health level is required to make migration feasible and worthwhile (Lu 2008; Rubalcava et al. 2007). This can operate at different stages of immigration. First in the decision-making phase, those with better health are more likely to contemplate international migration, as they perceive a greater chance of admission and a better prospect of settling in the destination. Second in the selection stage (for legal immigration), prospective immigrants with good health are more likely to gain admission while those with poor health may be deemed as inadmissible.

An understudied question is how immigrant health selection varies across destinations 
characterized by different immigration policies and health systems. To address this question, research needs to focus on newly arrived immigrants to avoid conflating health selection at arrival with health assimilation after arrival. Also, such research should compare immigrants at various destinations, rather than comparing immigrants with the respective native population in each destination (unless native-born populations across different countries share similar health profiles, which is often not the case). Furthermore, studying relative immigrant health selection at the two destinations helps circumvent the prevailing data limitations regarding the availability of information on health of non-migrants among the origin population. In a cross-destination comparison, direct comparisons of health of immigrants at different destinations can be carried out without data on the health of population in the origin country, insofar as we compare immigrant streams from the same source region or country.

\subsection{Immigration Policy, Health Screening, and Health System in Canada and the U.S.}

We now discuss several notable institutional differences between the two countries and how each dimension may affect immigrant health selection.

\subsubsection{Immigration Policy}

Canada has implemented an explicit point system to screen workers with special skills or high levels of education (Boyd 1976; Greenwood and McDowell 1991). The system seeks to enhance skilled immigration using educational attainment, English/French language proficiency, and occupational experience as markers of skills (Hiebert 2006). There has been an increasing emphasis on education and language proficiency over time. For example, since the early 2000s, prospective immigrants with a bachelor's degree received 20 points, double the points allocated to college and advanced degrees in the 1990s. Canada has other categories of immigration, including an employer nomination preference category via the Provincial Nominee program and 
the Canadian experience class (Pandey and Townsend 2011; Baglay 2012). This allows provinces to nominate immigrants, mostly workers with specific skills, to meet provincial needs. Despite prioritizing economic-based immigration, the Canadian immigration policy also seeks to preserve family unity by admitting family-based immigrants (Greenwood and McDonwell 1999; Challinor 2011). While the majority of immigrants to Canada are admitted as economic class migrants, still about $25 \%$ are admitted based on family ties (under the family class). The relevant family policy uses narrower definitions of eligible family members than in the U.S., especially for extended family members. In Canada, citizens and permanent residents may sponsor spouses and common law partners; dependent children under the age of 19; and parents and grandparents, if they show no need for social assistance from the government (Kelley and Trebilcock 2010). Only in rare instances can they sponsor other relatives. Different categories of family-based immigrants are subject to annual target levels set by the government.

The U.S. immigration system emphasizes family reunification, with unlimited admittance for immediate relatives of U.S. citizens, including spouses, unmarried children under 21, and parents (if the citizen is at least 21 years old). Further family-based preference is given to unmarried children of U.S. citizens and their children; spouses and children of legal permanent residents; married children of U.S. citizens and their spouses and children; and the siblings of U.S. citizens and their spouses and children, under fiscal year numerical limitations. The U.S. also allows employer-sponsored immigration, although the proportion of immigrants admitted under this mechanism has remained quite low. The U.S. Immigration Act of 1990 doubled the annual quota of employer-sponsored permanent resident immigration; it also created and expanded temporary immigration (H-1B and F1 visas) for specialized high-skilled workers (i.e., scientific research, information technology, and engineering) and students pursuing higher 
education (Vialet and Eig 1990). However, despite the increase in skilled immigration, family reunification remains the central pillar of the U.S. immigration policy.

The proportion of immigrants admitted based on skills or employment is remarkably higher in Canada than in the U.S. In 2010, over $66 \%$ of all new legal permanent residents in the U.S. were admitted for family reunification, compared to only $14 \%$ issued for employment. In Canada, by contrast, economic-class immigrants accounted for $67 \%$ of all legal immigrants in 2010, while family-class immigrants made up 21\% (Government of Canada 2012).

One difference to note is that the U.S. has had a large-scale undocumented immigrant population, primarily from Mexico (Passel and Cohn, 2012, Hoefer, Rytina, and Campbell 2006). This stream of immigrants has expanded dramatically since the mid-1990s. Estimates suggest that a little over a fourth of all immigrants are undocumented (about 11.7 million by 2012; Passel, Cohn and Gonzalez-Barrera 2013). The magnitude of undocumented immigration in Canada is much smaller, with estimates somewhere between 20,000 and 500,000, comprising less than $8 \%$ of total immigrants (Magalhaes, Carrasco, and Gastaldo 2010). The selection process of unauthorized immigrants is likely to be different from that of legal immigrants.

The undocumented enter outside the purview of the immigration system and tend to be more sensitive to economic conditions than to institutional factors. As with most existing data, we are unable to disentangle undocumented from documented immigrants. To evaluate the possible impact on our results, we carried out a sensitivity analysis excluding immigrants from Mexico, following earlier studies (Antecol et al. 2003; Borjas 1993; Picot and Hou, 2011).

Due to differences in immigration policies and geographic proximity of the U.S. to Mexico, the main source region of immigrants to Canada and the U.S varies. Europe and Asia are the top sending regions to Canada, and Latin America is the main sending region to the U.S. 
Even among immigrants from the same source country, those to Canada are on average more educated than their U.S. counterparts (Kaushal and Lu 2014).

\section{Implications for relative health selection of immigrants}

Previous research has demonstrated a positive education gradient on health (Cutler and LlerasMuney 2006; Kimbro et al., 2008) and regional variations in health; for example, Europeans and Asians have a better health profile than Latin Americans across a range of indicators, especially in BMI status (Tunstall-Pedoe et al. 1994; WHO 2010). In these respects, the higher human capital of Canadian immigrants and the larger proportion of Canadian immigrants from Europe and Asia is likely to result in more positive selection on health among Canadian than among U.S. immigrants (Cutler and Lleras-Muney 2006; Grossman 2000). That is, Canadian immigrants are likely to have better health than U.S. immigrants upon arrival. There is some supporting evidence on this premise. In a study of immigrants to Australia, Chiswick et al. (2008) demonstrate that immigrants who are selected for entry on economic success (i.e., skilled immigrants) have more favorable health outcomes than immigrants based on family reunification. People with low human capital may be less likely to apply for immigration to Canada in the first place because they perceive the chance of successful admission to be low. Even if they do apply, the chance of admission can be slim. These considerations, in contrast, are less relevant for family-based immigrants, who account for a larger share of U.S. immigrants. Moreover, the differential proportion of skill-based immigrants in Canada and the U.S. can have important implications for family-based immigration. Because the characteristics of family members (e.g., human capital, health) are often correlated (Sweetman and Warman 2010), the more favorable selection of principal immigrants in Canada can lead to a more positive selection of their family members. These together result in a greater level of positive health selection for 
Canadian immigrants.

\subsection{Health Screening}

Canada and the U.S. implement broadly similar health screening procedures for immigrants (Beiser 2005; see online Appendix A for a summary of the two systems). In both countries, permanent residents and temporary immigrants staying for over six months are subject to health screening. The screening includes a comprehensive review of medical history, standard physical examinations, and basic blood tests and x-rays. It covers a range of communicable diseases, chronic conditions, mental health conditions, and substance abuse.

However, there are a few noticeable differences. The procedures are more extensive in Canada, involving a more in-depth physical exam and an additional urine test. More importantly, the selection criteria differ. In the U.S., the emphasis is placed on ensuring public health and safety by screening for communicable diseases and for mental health disorders and substance abuse (US Department of State, 2016). In Canada, beyond these emphases, the system further screens for health conditions that can cause excessive demand on social services (i.e., serious chronic conditions) (Government of Canada, 2016a). This serves to contain public expenditures in a context with universal healthcare.

It should be noted that health screening in Canada does not automatically result in the rejection of applicants with a serious health condition. Rather, an assessment is made of the estimated cost of treatment and the resource impact of the specific condition before a final decision is made. As long as the cost of treatment is less than the allowed value (around $\$ 6,000$ per year), immigrants are not considered medically inadmissible due to excessive demand. Also, in both countries, immigrant applicants can challenge a medical-based rejection through an appeal process, which allows many to overcome inadmissibility on health grounds. However, the 
overall rejection rate tends to be higher in Canada than in the U.S., and a notable proportion of the rejected is likely to have costly health conditions (Laroche 2000; Wasem 2014).

\section{Implications for relative health selection of immigrants}

Given the differences in the health criteria for admission, prospective immigrants with poor health, especially serious health impairments, are more likely to be deemed inadmissible in Canada. The health screening may also deter those with serious health impairments to apply to immigrate. Taken together, the system in Canada is more likely to screen out or deter immigrants with serious health impairments considering their emphasis on costly health conditions. If so, we would expect this mechanism to manifest mainly through serious health conditions-leading to lower rates of these conditions among new Canadian immigrants than new U.S. immigrants.

\subsection{Health Care System}

Another contextual difference that may affect immigrant health selection between Canada and the U.S. is their distinct health care systems. Health care in Canada is provincially administered through a publicly financed system. It is essentially free at the point of use (except for dental care and prescription drug) (Zuberi 2006). This system has reduced disparities in access to care, and resulted in more equitable health outcomes (Ross, Wolfson, Dunn, Berthelot, Kaplan, and Lynch 2000).

The U.S. health care system, in contrast, has been largely based on private insurance provided through the workplace. Public health insurance has been traditionally only provided to the poor, the elderly, children, military personnel and veterans. More recently, the Patient Protection and Affordable Care Act (PPACA) was passed in 2010 to ensure expanded or subsidized health insurance coverage to a wider population, as well as to improve coverage quality. However, under PPACA, individuals still purchase private health insurance, though 
some may be eligible for tax credits to help offset the costs of insurance premiums. At the national level, over 36 million Americans were uninsured in 2014; the proportion is higher among the foreign-born population (27\% vs. 9\% for natives; Zong and Batalova 2016). Most immigrants are ineligible for the health care coverage expansion through PPACA, including legal immigrants without permanent resident status (i.e., temporary immigrants), some permanent residents for less than five years (due to the 1996 Personal Responsibility and Work Opportunities Reconciliation Act), and unauthorized immigrants (Capps and Fix 2013; Daniels and Ladin 2014; Tiffany 2016).

\section{Implications for relative health selection of immigrants}

To the extent that health care systems factor into migration decision-making, Canada may be a more attractive destination to persons with relatively poor health. The less extensive public health care in the U.S. can serve as a disincentive for prospective immigrants with health impairments. This would lead to a more positive health selection favoring immigrants to the U.S. However, extant research examining the relationship between destination welfare generosity and migrants' location choice is inconclusive, pointing to only weak evidence that immigrants with greater welfare needs tend to choose destinations with more generous social services (Dodson 2001; Kaushal 2005; Borjas 1999; De Giorgi and Pellizari 2006; Barrett and McCarthy 2008). Even for immigrants who give considerable weight to the welfare system in destination countries, immigration intention does not necessarily translate into the ability to immigrate. This is especially true for immigration to Canada, which adopts a stringent selection system. Thus, the health of new immigrants to the two countries is less likely to be affected by considerations related to the health care system than immigration policy and health screening. 


\section{Data, Variables, and Methods}

\subsection{Data}

We used multiple waves of nationally representative cross-sectional data over the period of 2001 and 2012: the National Health Interview Survey (NHIS), conducted annually, for 20012012, and the Canadian Community Health Survey (CCHS), conducted biannually for 2001, 2003,2005 , and annually for 2007-2012. We chose these two surveys because they offered comparable health measures and provided an adequate sample size of new immigrants.

We pooled the data for the two countries over time. The analytic sample is immigrants (foreign-born) aged 18 to 60 years who have been in the host country for less than one year prior to each respective survey (referred to as "new immigrants"). We focused on new immigrants because their health best captures health status upon arrival, or health selection, and is least confounded with health assimilation. Neither NHIS nor CCHS collected information on the health of immigrants prior to arrival.

The analytic sample included 1,853 and 501 new immigrants in the U.S. and Canada between 2001 and 2012. Because the Canadian sample was smaller, we conducted a sensitivity analysis including new immigrants in Canada up to 1.5 years. The Canadian sample increased to 1,269 .

\subsection{Measures}

The dependent variables were overweight/obesity status and chronic conditions. We created a dichotomous indicator based on the WHO standard, with body mass index greater than or equal to 25 coded as overweight or obese.

Both surveys asked respondents whether they have been diagnosed by a health care professional with a host of chronic conditions. We constructed a dichotomous measure indicating 
whether the respondent had any serious chronic condition, including cancer, diabetes, heart disease, and stroke. We created a second dichotomous measure indicating the presence of any chronic condition, which additionally includes less serious but nonetheless debilitating conditions such as asthma, high blood pressure, ulcer, and arthritis. These chronic conditions represent all the chronic indicators comparable across all survey waves and across countries.

The key independent variable was equal to 1 if an immigrant lived in the U.S., and 0 if he or she lived in Canada. We also distinguished immigrants from different sending regions. NHIS provided information on source regions of immigrants. To maintain consistency across the two datasets, we categorized the sending country variable in CCHS to match with the available region categories in NHIS. This strategy yielded sufficient sample size for each region. The final categories were Latin America, Europe (including a very small number of immigrants from Australia and New Zealand), Africa and the Middle East, South-East Asian (including South and Southeast Asia), and East Asia. We did not separate Mexico from Latin America because there were very few immigrants from Latin America to Canada, and a large proportion of these immigrants came from Mexico.

Other control variables included age and age squared, gender, marital status (single or common-law; married; widowed, divorced or separated), education (less than high school; high school; some college or associate's degree; Bachelor's degree or higher), and survey period categories (2001-2003; 2004-2007; 2008-2012). We ran additional analyses including age as a categorical variable. The results were very similar. We thus used age and age squared in all models for parsimony. To adjust for geographic variations in migrant networks, we controlled for the percentage of immigrants from a respondent's sending region in his or her province/region of residence based on the census estimates. 
In both datasets, the level of missing data was generally low. In the analysis, we drop cases with any missing data, which together accounted for less than $10 \%$ of the sample.

\subsection{Statistical Analysis}

We used logistic regressions for the analyses. The baseline model is:

$L\left(H_{i s d}\right)=\alpha \times U S_{i s}+\boldsymbol{X B}$

where $L($.$) is the link function for the underlying logit probability. H_{\text {isd }}$ denotes health status of immigrant $i$ from sending region $s$ who recently arrived in destination $d$ (Canada or the U.S.). The variable $U S_{i s}$ is equal to 1 if an immigrant currently lives in the U.S., and 0 if he or she lives in Canada. The vector $\mathbf{X}$ denotes other covariates in the model.

To disentangle different processes producing the observed difference in the health of new immigrants, we estimated equations 2 and 3, which further control for the sending region of immigrants $\left(S_{s}\right)$ and then education $\left(E_{i s d}\right)$. The two models allow us to assess the extent to which differential health selection patterns observed in equation 1 can be accounted for by different sending region composition of the two streams of immigrants, and by different human capital composition of immigrants from the same sending region.

$L\left(H_{i s d}\right)=\alpha \times U S_{i s}+\boldsymbol{X B}+\gamma \times S_{S}$

$L\left(H_{i s d}\right)=\alpha \times U S_{i s}+\boldsymbol{X B}+\gamma \times S_{s}+\delta \times E_{i s d}$ (3)

We conduct an additional analysis that includes interaction terms between $U S_{i s}$ and survey year to examine whether relative health selection of immigration has changed over time. The interaction terms are not significant and thus not included in the main analysis. This is not unexpected because major immigration policy changes in the two destinations precede our study period. We also run separate models for men and women, which yield similar results for both sexes. This led us to combine men and women in the main analysis. 
In all models, we adjusted for clustering of immigrants by sending-receiving region combinations using the Huber-White sandwich estimator and obtained robust standard errors (White 1982). Without such adjustments, the results are sensitive to the size of the immigrant samples from different source regions. We derived odds ratios and 95\% confidence intervals from the results. We performed all analyses using Stata 14 (StataCorp 2015).

\section{Results}

Descriptive statistics are shown in Table 1. New immigrants in the U.S. were more likely to be overweight or obese (38\% vs. $29 \%$ ) and slightly more likely to have chronic conditions $(12 \%$ vs. $10 \%)$ than new Canadian immigrants. Fewer new immigrants reported serious chronic conditions. Indeed, the rate in Canada was so low that it did not meet Statistics Canada's threshold for public release. For these health indicators, the rate was substantially lower for new immigrants than for the respective native population in each country. This was consistent with the "healthy migrant effect". Also, when comparing the health of the native-born population in the two countries, Canadians were generally healthier than Americans. About 62\% Americans were overweight or obese, which was true for $53 \%$ of Canadians. The rate of having a serious chronic condition for Americans was 15\%, which doubled the rate for Canadians (7\%).

With respect to other characteristics, there was a marked difference in the sending regions of immigrants. In the U.S., $57 \%$ of new immigrants were from Latin America, followed by South-East Asia (18\%). Other sending regions made up a similar proportion of immigrants (ranging between $7 \%$ and $9 \%$ ). By contrast, in Canada the primary source regions of new immigrants were South-East Asia (29\%), East Asia (20\%), and Europe (23\%). Latin American immigrants accounted for $12 \%$ of new immigrants, fewer than African and Middle Eastern immigrants (16\%). Another important distinction was education. Consistent with the emphasis 
on human capital in Canada's point system, $82 \%$ of new immigrants to Canada had at least some college education, compared to only $44 \%$ of new U.S. immigrants.

Table 2 displays the results for overweight/obesity. In Model 1, a higher proportion of U.S. immigrants were overweight or obese than their peers in Canada, but the coefficient was marginally significant at the 0.05 level $(\mathrm{OR}=1.609 ; 95 \% \mathrm{CI}=0.996,2.598)$. Once we control for sending regions in Model 2, that is, comparing new immigrants from the same sending region, the odds of overweight and obese were $28 \%$ higher for those in the U.S. than those in Canada $(\mathrm{OR}=1.280 ; 95 \% \mathrm{CI}=1.077,1.522)$. Model 3 additionally controlled for education of new immigrants. The cross-country difference was further reduced and became non-significant $(\mathrm{OR}=1.153 ; 95 \% \mathrm{CI}=0.961,1.383)$. In other words, the different rate of overweight and obesity for new immigrants between the two countries are partly explained by the different sending region composition and education of the two streams of immigrants.

Table 2 demonstrated several other interesting findings. There was considerable regional variation in the risk of overweight and obesity. New immigrants from Africa/Middle East and Latin America were more likely to be overweight or obese than European immigrants. The opposite was true for Asian immigrants. The odds were $64 \%$ lower for immigrants from East Asia than those from Europe. Also, the odds of overweight and obesity were higher for male immigrants and increased with age. Education reduced the risk of overweight and obesity and this was particularly true for those with some college education comparing to those with less than high school education.

Results for chronic conditions were presented in Table 3. There was a pronounced crosscountry difference with respect to serious chronic conditions. The odds of having any serious chronic condition were 3 times as high for new U.S. immigrants as for new Canadian immigrants 
(Model 1) $(\mathrm{OR}=3.040 ; 95 \% \mathrm{CI}=1.720,5.375)$. Because serious chronic conditions were unlikely to develop within one year of arrival, these results provided strong indicators that U.S. immigrants were more likely to come with serious chronic conditions than Canadian immigrants. It is probable that for a small number of immigrants, chronic conditions are diagnosed post arrival. But even if true, Canadian immigrants are more likely to receive such a diagnosis than their U.S. counterparts, considering the universal health provision in Canada. This would suggest a greater cross-country difference in serious chronic conditions that favors Canadian immigrants. Controlling for sending regions of immigrants (Model 2) and education (Model 3) reduced the cross-country difference slightly. But the higher odds of serious chronic conditions remained large and significant. Even among immigrants from the same sending region and with the same level of education, the odds of having serious chronic conditions were over 1.6 times higher for those coming to the U.S. than those to Canada (OR $=2.623 ; 95 \% \mathrm{CI}=1.055,6.521)$. The cross-country difference in serious chronic conditions was not entirely explained by different human capital and region composition of immigrants to the two countries. Hence, U.S. immigrants remain more likely to have a serious chronic condition than are Canadian immigrants. In terms of all chronic conditions, the difference was small and non-significant (bottom panel of Table 3, which controlled the same set of covariates as in the top panel of the table).

Because the Canadian sample of new immigrants was smaller than the U.S. sample, we estimated all models based on the 1.5-year new immigrant sample in Canada. Results are presented in Table 4. For parsimony, we showed only the estimates for the US-Canada difference. The results were generally consistent with those in Tables 2 and 3. Specifically, the more positive selection in overweight or obese in Canada is explained by sending region 
composition and education. There are large gaps in serious chronic health conditions, which remain after controlling for sending region and education of immigrants.

We also excluded Mexican immigrants from the sample, as they comprise a large fraction of immigrants, especially undocumented immigrants, to the U.S. Results are shown in Table 5. They are based on the 1.5-year sample in Canada because it provides a larger sample size for restricted-sample analyses. The results were largely consistent. After adjusting for sending region and education, the difference in obesity or overweight becomes non-significant. Also, non-Mexican U.S. immigrants continue to have a higher risk of having serious chronic conditions and multiple chronic conditions than non-Mexican immigrants in Canada, after controlling for compositional differences of the two streams of immigrants. This is less true for any chronic condition. Overall, the results suggest that our findings are not driven primarily by the disproportionately large number of Mexican immigrants in the U.S.

\section{Discussion}

We studied relative health selection of immigrants to Canada and the U.S. by comparing the health of new immigrants in the two countries. The results showed that new immigrants to Canada were less likely to be overweight/obese or have a serious chronic condition than new immigrants to the U.S. The differential health selection with respect to overweight/obesity status was driven by immigrant selection in source regions and in education. Canada drew immigrants mainly from Asia and Europe and the U.S. mainly from Latin American countries. The two sets of regions tend to have different health profiles in terms of weight status (World Health Organization, 2008). Also, comparing immigrants from the same sending region, Canadian immigrants were more highly educated than U.S. immigrants (Kaushal and Lu 2015), and the higher level of human capital contributed to explaining healthier weight status. These findings 
were generally aligned with the prediction that the greater emphasis on human capital-based immigration (i.e., the point system) in Canada has led to a distinct group of immigrants in terms of source regions and education, and subsequently immigrants with better health at arrival.

New immigrants in the U.S. remained significantly more likely to have serious chronic conditions than their Canadian counterparts even after accounting for compositional differences in sending regions and education. This pattern suggested that there may be other contributing factors. One possibility is that chronic conditions are shaped by cumulative socioeconomic background that may not be entirely captured by educational level at arrival. Also, health screening may play a role. Because Canada places an emphasis on screening for costly health conditions that can "cause excessive demand on health or social services", prospective immigrants with serious chronic illnesses may be less likely to apply to Canada (deterrent effect), and when they do apply, may be less likely to be granted admission. This explanation is plausible since we observe a greater difference in selection of serious chronic conditions than less severe ones. This result lends some evidence to the speculation that immigrant health screening can have important implications for the health profile of immigrants (McDonald and Kennedy 2004).

We did not find a strong relationship between the generosity of health care system and immigrant destination choice. If such a relationship were to manifest, immigrants with poor health would be more likely to choose Canada for its better public health provision and we would find a health selection pattern opposite of what we observed. Our result is similar to research findings in related studies on welfare generosity that have failed to find a link between immigrant location choices (inter-state mobility) and generosity of state-level welfare programs (Kaushal 2005; Borjas 1999; Barrett and McCarthy 2008). Our study further expands the debate 
to the context of international migration to different countries and suggests that immigration decision-making is not heavily shaped by healthcare systems in destination countries.

This study has raised an important methodological consideration about the choice of appropriate comparison group. Studying immigrant health selection across destinations by comparing immigrant with the respective native population can yield misleading results. In our data, the native population in Canada fared better than their U.S. counterparts on various health measures. If we were to compare immigrants with the native population in each country respectively (as shown in Table 1 and our additional regression analyses in Appendix B), we would have reached a different conclusion that new immigrants in the U.S. were healthier than new Canadian immigrants because their health advantage over the native population is greater. But this is essentially due to the better health status of the Canadians than Americans, and not due immigrant selection.

The present study has a few limitations. First, we lack detailed sending country information and rely on relatively small sample size in order to focus on very recent immigrants. We conduct a range of sensitivity analyses, which point to consistent findings and thus increase our confidence in the robustness of our results. Second, it would be ideal to have information on the health of immigrants before or upon migration to better capture the process of selection. Finally, we did not have information to address differential return migration with respect to health (i.e., "salmon bias", or return of unhealthy immigrants; Palloni \& Arias, 2004). Given Canada's generous health care system, if health-related return migration were to occur, it may be less prevalent for Canadian immigrants than for U.S. immigrants. The fact that we still observe a more positive health profile among new immigrants to Canada, even in the face of greater 
incentives for unhealthy immigrants to remain in Canada than in the U.S., suggests that the initial positive health selection of Canadian immigrants would be stronger.

Our comparative study provided important insight into our understanding of how immigration-related policies shape the health of immigrants upon arrival. Despite the fact that immigrants are healthier on average than the native population (Fennelly 2007), the level of their positive health selection differs across context. The finding of a more positive health selection of Canadian immigrants highlights the role of immigrant receiving context, such as immigrationrelated policies that select immigrants based on their economic and demographic characteristics, in reconfiguring the characteristics of newcomers, including the characteristics beyond those that directly constitute the selection criteria (Chiswick et al. 2008). Selecting immigrants on factors associated with favorable labor market outcomes, such as human capital and other productivityrelated characteristics, is likely to result in favorable selectivity of immigrants on related dimensions such as health. Hence, immigration policy regimes that prioritize employability versus family reunification can have important implications not only for the human capital composition of immigrants but also for their heath traits at migration. The findings in this study are relevant for public policy debates regarding the mechanisms for immigrant admission.

Differences in immigration policy are coupled with differences in formal health screening system as part of the immigration process (US Department of State 2016; Government of Canada 2016a). Although immigrant-receiving societies have general requirements concerning the health of prospective immigrants, the range of health conditions emphasized in the screening varies across destinations. Most health screening systems are intended to minimize risks to public safety and public health. Some countries, such as Canada and Australia, take additional measures to ensure that public expenditures on health services are contained and the native-born are not 
crowded out from health services. To the extent that prospective immigrants with certain medical conditions are disqualified or discouraged, the health screening process at the time of entry also shapes the health profile of immigrants. Thus, the more positive health selection of Canadian immigrants, especially with respect to chronic conditions, is likely to be magnified by the emphasis in Canada's immigrant health screening on identifying costly health conditions, which can deter immigrants with such conditions from applying or subject them to rejection (Laroche 2000).

The differential health selection patterns we identified are likely to continue in the foreseeable future. There has been an increasing emphasis on human capital in Canada over time (Ferrer, Picot and Riddell 2014). Since the early 2000s, the points allocated to college and advanced degrees doubled. The most recent change was implemented as of January 2015, when a new Express Entry system for economic-class immigrants was put in place (Government of Canada 2016b). The new system gives priority to immigrants who have secured pre-arranged employment (in contrast to previous cohorts of immigrants who were expected to seek employment after admission). Insofar as employability and health are positively associated, this policy change may further strengthen the positive health selection of Canadian immigrants.

It is important to note that our findings did not suggest that U.S. immigrants were unhealthy. In fact, on average they were healthier than the native-born population. But compared to their peers from the same sending region to Canada, a higher percentage of new U.S. immigrants were overweight/obese or suffered from serious chronic conditions. The latter group are in particular need of health care services upon arrival. To the extent that immigration-related policies shape the health status of immigrant at arrival, they are likely to have implications for immigrants' health trajectories and public health of destination country. This study focused on 
the process of health selection, not health assimilation. The difference in the initial health of immigrants upon arrival in Canada and the U.S., together with different health care systems, can set the two streams of immigrants on divergent health trajectories. The preexisting health conditions that a higher portion of U.S. immigrants carries with them, together with their relatively low level of health insurance coverage (Kaushal and Kaestner 2013), could exacerbate the unmet health needs of U.S. immigrants. This points to the need for health program planning for newly arrived immigrants in host societies. This research provides a baseline understanding of immigrant health at arrival. Future studies can examine how the health trajectories of immigrants differ in the two countries. Continued knowledge development in the area of immigrant health selection and health assimilation can inform health policy as well as practice. 


\section{References}

Abraido-Lanza, Ana F., Maria T. Chao, and Karen R. Florez. 2005. "Do healthy behaviors decline with greater acculturation?: Implications for the Latino mortality paradox." Social Science \& Medicine 61(6):1243-1255.

Akresh, Ilana Redstone and Reanne Frank. 2008. "Health Selection among New Immigrants." American Journal of Public Health 98(11):2058.

Antecol, Heather, Deborah A Cobb-Clark and Stephen J Trejo. 2003. "Immigration Policy and the Skills of Immigrants to Australia, Canada, and the United States." Journal of Human Resources 38(1):192-218.

Antecol, Heather and Kelly Bedard. 2006. "Unhealthy Assimilation: Why Do Immigrants Converge to American Health Status Levels?". Demography 43(2):337-60.

Barrett, Alan and Yvonne McCarthy. 2008. "Immigrants and Welfare Programmes: Exploring the Interactions between Immigrant Characteristics, Immigrant Welfare Dependence, and Welfare Policy." Oxford Review of Economic Policy 24(3):542-59.

Beiser, Morton. 2005. "The Health of Immigrants and Refugees in Canada." Canadian Journal of Public Health/Revue Canadienne de Sante'e Publique:S30-S44.

Borjas, George J. 1993. "Immigration Policy, National Origin, and Immigrant Skills: A Comparison of Canada and the United States." Pp. 21-44 in Small Differences That Matter: Labor Markets and Income Maintenance in Canada and the United States, edited by D. Card and R. B. Freedman: University Of Chicago Press.

Borjas, George J. 1999. "Immigration and Welfare Magnets." Journal of Labor Economics 17(4):607-37.

Boyd, Monica. 1976. "Immigration Policies and Trends: A Comparison of Canada and the United States." Demography 13(1):83-104.

Camarota, Steven A. 2011. "A Record-setting Decade of Immigration, 2000 to 2010." Washington, DC: Center for Immigration Studies.

Capps, Randy and Michael Fix. 2013. "Immigration Reform: A Long Road to Citizenship and Insurance Coverage." Health Affairs 32:639-642.

Challinor, AE. 2011. "Canada's Immigration Policy: A Focus on Human Capital." Migration Information Source.

Chiswick, Barry R., Yew Liang Lee, and Paul W. Miller. "Immigrant selection systems and immigrant health." Contemporary Economic Policy 26.4 (2008): 555-578.

Cunningham, Solveig Argeseanu, Julia D Ruben and KM Venkat Narayan. 2008. "Health of Foreign-Born People in the United States: A Review." Health \& place 14(4):623-35.

Cutler, David M. and Adriana Lleras-Muney. 2006. "Education and Health: Evaluating Theories and Evidence." NBER Working Paper No. w12352. Available at SSRN: http://ssrn.com/abstract=913315

Daniels, Norman and Keren Ladin. 2014. "Immigration and Access to Health Care." In Routledge Companion to Bioethics, edited by J. D. Arras, R. Kukla, E. Fenton, T. Routledge, and F. Routledge.

De Giorgi, Giacomo and Michele Pellizzari. 2006. "Welfare Migration in Europe and the Cost of a Harmonised Social Assistance." IZA Discussion Paper (No. 2094).

De Maio, Fernando G and Eagan Kemp. 2010. "The Deterioration of Health Status among Immigrants to Canada." Global Public Health 5(5):462-78.

Fennelly, Katherine. 2007. "The" healthy migrant" effect." Minnesota Medicine 90(3): 51-53. 
Ferrer, Ana M., Garnett Picot, and William Craig Riddell. 2014. "New directions in immigration policy: Canada's evolving approach to the selection of economic immigrants."

International Migration Review 48(3): 846-867.

Government of Canada. 2012. Immigration, Refugees and Citizenship Canada: Facts and figures. Retrieved: http://www.cic.gc.ca/english/resources/statistics/facts2012/permanent/01.asp.

Government of Canada. 2016a. Citizenship and Immigration Canada, Panel Members'

HANDBOOK 2013. Retrieved: http://www.cic.gc.ca/english/resources

/publications/dmp-handbook/index.asp.

Government of Canada. 2016b. Express Entry System. Retrieved:

http://www.cic.gc.ca/english/resources/publications/express-entry-presentation-

immigrants.asp

Dodson, Marvin E. 2001. "Welfare Generosity and Location Choices among New United States Immigrants." International Review of Law and Economics 21(1):47-67.

Greenwood, Michael J and John M McDowell. 1991. "Differential Economic Opportunity, Transferability of Skills, and Immigration to the United States and Canada." The Review of Economics and Statistics: 612-23.

Grossman, Michael. 2000. "The Human Capital Model." Handbook of health economics 1:347408.

Hiebert, Daniel. 2006. "Winning, Losing, and Still Playing the Game: The Political Economy of Immigration in Canada." Tijdschrift voor economische en sociale geografie 97(1):38-48.

Hoefer, Michael, Nancy Rytina, and Bryan C. Baker. 2006. Estimates of the Unauthorized Immigrant Population Residing in the United States: January 2006. Population Estimates, Office of Immigration Statistics, Department of Homeland Security

Jasso, Guillermina, Douglas S Massey, Mark R Rosenzweig and James P Smith. 2004. "Immigrant Health: Selectivity and Acculturation." Critical perspectives on racial and ethnic differences in health in late life:227-66.

Kaushal, Neeraj. 2005. "New Immigrants' Location Choices: Magnets without Welfare." Journal of Labor Economics 23(1):59-80.

Kaushal, Neeraj, and Robert Kaestner. 2013. "Acculturation and Health Insurance of Mexicans in the USA." Review of International Economics 21(2): 233-248.

Kaushal, Neeraj and Yao Lu. 2014. "Recent Immigration to Canada and the United States: A Mixed Tale of Relative Selection." International Migration Review 49(2):279-522.

Kelley, Ninette and Michael Trebilcock. 2010. The Making of the Mosaic: A History of Canadian Immigration Policy. Toronto: University of Toronto Press.

Kennedy, Steven, Michael P Kidd, James Ted McDonald and Nicholas Biddle. 2014. "The Healthy Immigrant Effect: Patterns and Evidence from Four Countries." Journal of International Migration and Integration:1-16.

Kimbro, Rachel Tolbert, et al. 2008. "Race, ethnicity, and the education gradient in health." Health Affairs 27(2):361-372.

Lara, Marielena, Cristina Gamboa, M Iya Kahramanian, Leo S Morales and David E Hayes Bautista. 2005. "Acculturation and Latino Health in the United States: A Review of the Literature and Its Sociopolitical Context." Annu. Rev. Public Health 26:367-97.

Laroche, Mireille. 2000. "Health Status and Health Services Utilization of Canada's Immigrant and Non-Immigrant Populations." Canadian Public Policy/Analyse de Politiques:51-75.

Lasser, Karen E., David U. Himmelstein, and Steffie Woolhandler. 2006. "Access to care, health status, and health disparities in the United States and Canada: results of a cross-national 
population-based survey." American Journal of Public Health 96(7):1300-1307. LopezGonzalez, Lorena, Veronica C Aravena and Robert A Hummer. 2005. "Immigrant Acculturation, Gender and Health Behavior: A Research Note." Social Forces 84(1):58193.

Lu, Yao. 2008. "Test of the 'Healthy Migrant Hypothesis': A Longitudinal Analysis of Health Selectivity of Internal Migration in Indonesia." Social science \& medicine 67(8):1331-39. Magalhaes, Lilian, Christine Carrasco and Denise Gastaldo. 2010. "Undocumented Migrants in Canada: A Scope Literature Review on Health, Access to Services, and Working Conditions." Journal of immigrant and minority health / Center for Minority Public Health 12(1):132-51.

McDonald, James Ted, and Steven Kennedy. 2004. "Insights into the 'healthy immigrant effect': health status and health service use of immigrants to Canada." Social Science \& Medicine 59(8):1613-1627.

Nauman, E., VanLandingham, M., Anglewicz, P., Patthavanit, U., \& Punpuing, S. 2015. "Ruralto-urban Migration and Changes in Health among Young Adults in Thailand. Demography 52(1):233-257.

Newbold, K Bruce and David Neligan. 2012. "Disaggregating Canadian Immigrant Smoking Behaviour by Country of Birth." Social science \& medicine 75(6):997-1005.

O'Neill, June E., and Dave M. O'Neill. 2007. "Health status, health care and inequality: Canada vs. the US." Forum for Health Economics \& Policy. Vol. 10. No. 1.

Palloni, Alberto and Elizabeth Arias. 2004. "Paradox Lost: Explaining the Hispanic Adult Mortality Advantage." Demography 41(3):385-415.

Passel, Jeffrey S., and D. Cohn. 2012. "US foreign-born population: How much change from 2009 to 2010." Washington, DC: Pew Research Center's Hispanic Trends Project.

Passel, Jeffrey S., D. Cohn, and Ana Gonzalez-Barrera. 2013. "Population decline of unauthorized immigrants stalls, may have reversed." Washington, DC: Pew Hispanic Center: 38.

Picot, Garnett and Feng Hou. 2011. "Preparing for Success in Canada and the United States: The Determinants of Educational Attainment among the Children of Immigrants." Statistics Canada Analytical Branch Studies Working Paper (332).

Rubalcava, Luis N, Graciela M Teruel, Duncan Thomas and Noreen Goldman. 2008. "The Healthy Migrant Effect: New Findings from the Mexican Family Life Survey." Journal Information 98(1).

Siddiqi, Arjumand, India J. Ornelas, Kelly Quinn, Dan Zuberi, and Quynh C. Nguyen. 2013. "Societal context and the production of immigrant status-based health inequalities: a comparative study of the United States and Canada." Journal of Public Health Policy $34(2): 330-344$.

StataCorp. 2015. "Stata Statistical Software: Release 14." College Station, TX: StataCorp LP. Statistics Canada. 2013. "Immigration and ethnocultural diversity in Canada."

Tiffany D. Joseph. 2016. "What Healthcare Reform Means for Immigrants: A Comparison of the Affordable Care Act and Massachusetts Health Reforms." Journal of Health Policy, Politics, and Law 41: 101-116.

Tunstall-Pedoe, Hugh, et al. 1994. "Myocardial infarction and coronary deaths in the World Health Organization MONICA Project. Registration procedures, event rates, and casefatality rates in 38 populations from 21 countries in four continents." Circulation 90(1)1994:583-612. 
US Department of State. 2016. Interview preparation - Medical examination FAQs. Retrieved: https://ravel.state.gov/content/visas/en/immigrate/immigrantprocess/interview/prepare/medical-exam-faqs.html.

Vialet, Joyce C. and Larry M. Eig. 1990. "Immigration Act of 1990 (P.L. 101-649)." Washington, D.C.: Congressional Research Service.

Wasem, Ruth Ellen. 2014. "Immigration Policies and Issues on Health-Related Gruops for Exclusion." Washington, D.C.: Congressional Research Service.

World Health Organization. 2008. Global Health Observatory (GHO) data - Mean Body Mass Index (BMI). Retrieved: http://www.who.int/gho/ncd/risk_factors/bmi_text/en/.

White, Halbert. 1982. "Maximum Likelihood Estimation of Misspecified Models." Econometrica: Journal of the Econometric Society1982: 1-25.

Zong J, Batalova J. 2016. Frequently Requested Statistics on Immigrants and Immigration in the United States. Migration Information Source. Retrieved :

http://www.migrationpolicy.org/article/frequently-requested-statistics-immigrants-andimmigration-united-states.

Zuberi, Dan. 2006. Differences That Matter: Social Policy and the Working Poor in the United States and Canada: Cornell University Press. 
Table 1. Sample Description

\begin{tabular}{lcc|cc}
\hline & \multicolumn{2}{c|}{ Canada } & \multicolumn{2}{c}{ United States } \\
\cline { 2 - 5 } & $\begin{array}{c}\text { Immigrants } \\
(<1 \text { yr })\end{array}$ & $\begin{array}{c}\text { Native- } \\
\text { Born }\end{array}$ & $\begin{array}{c}\text { Immigrants } \\
(<1 \text { yr })\end{array}$ & $\begin{array}{c}\text { Native- } \\
\text { Born }\end{array}$ \\
\hline Health Outcomes & 0.29 & 0.53 & 0.38 & 0.62 \\
\hline Overweight or Obese & 0.10 & 0.32 & 0.12 & 0.46 \\
Presence of a Chronic Condition & -- & 0.07 & 0.03 & 0.15 \\
Presence of a Serious Chronic Condition & & & & \\
\hline Region of Origin & 0.12 & -- & 0.57 & -- \\
\hline Mexico, South \& Central Americas & 0.23 & -- & 0.07 & -- \\
Europe & 0.16 & -- & 0.09 & -- \\
Africa \& Middle East & 0.29 & -- & 0.18 & -- \\
South-East Asia & 0.20 & -- & 0.08 & - \\
East Asia & & & & \\
\hline Sample Characteristics & 32.19 & 39.80 & 30.86 & 38.76 \\
\hline Age & 0.51 & 0.47 & 0.53 & 0.48 \\
Male & 0.37 & 0.43 & 0.42 & 0.31 \\
Single/common-law & 0.60 & 0.45 & 0.52 & 0.53 \\
Married & 0.03 & 0.13 & 0.06 & 0.15 \\
Widowed/divorced/separated & 0.06 & 0.15 & 0.38 & 0.11 \\
Less than high school & 0.13 & 0.20 & 0.18 & 0.30 \\
High school & 0.31 & 0.48 & 0.14 & 0.33 \\
Some college & 0.51 & 0.17 & 0.30 & 0.26 \\
Bachelor's Degree or higher & 501 & 342,983 & 1,853 & 468,728 \\
\hline$N$ & & & & \\
\hline Sample sinyyyyy & & & & \\
\hline
\end{tabular}

*Sample sizes reflect analytic sample for self-rated health models. Descriptive results for immigrants for Canada on serious chronic could not be released because the low sample sizes did not meet Statistics Canada disclosure rules. The rules stipulate that proportions with low cell counts for the numerator or denominator may not be released. Specifically, the low number of recent immigrants with a serious chronic condition in CCHS precludes release of this statistic. 


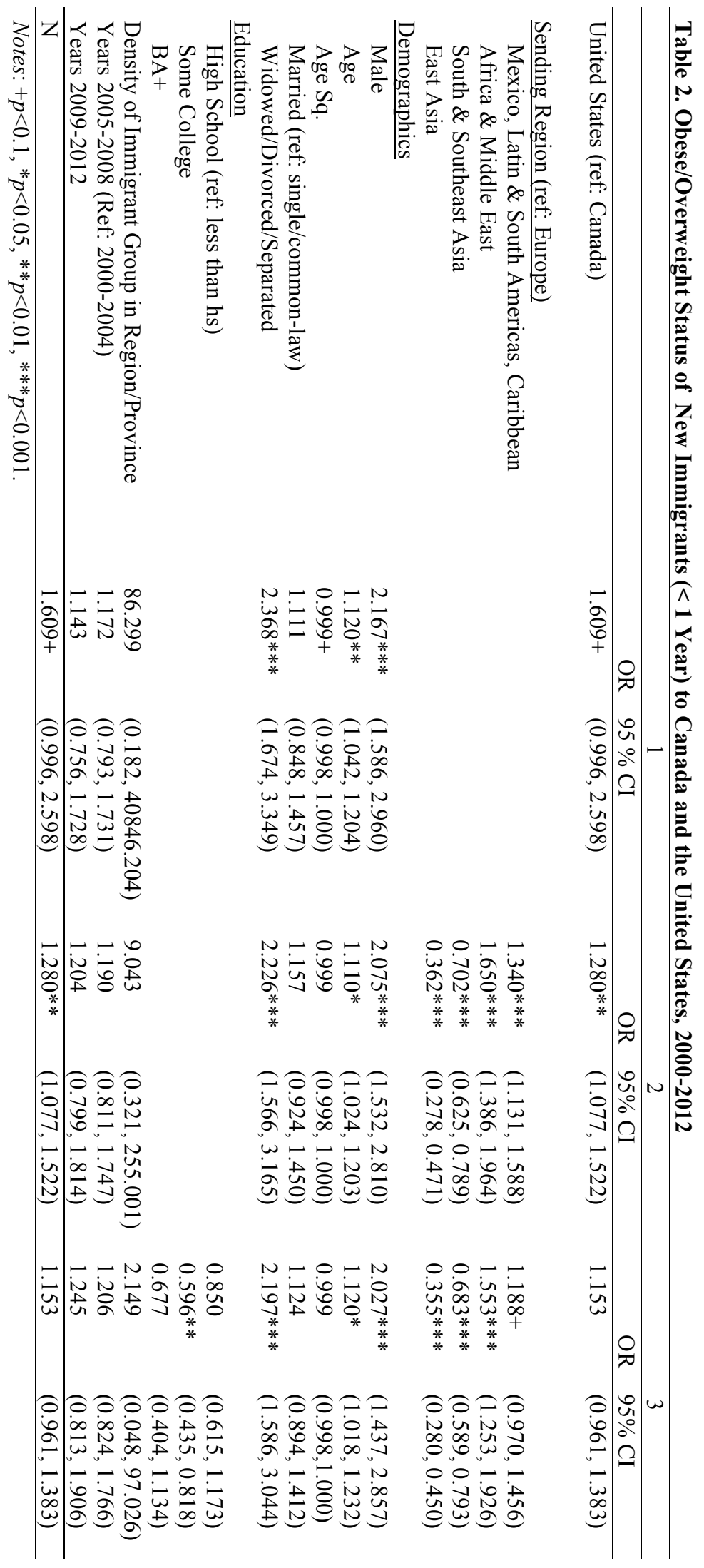




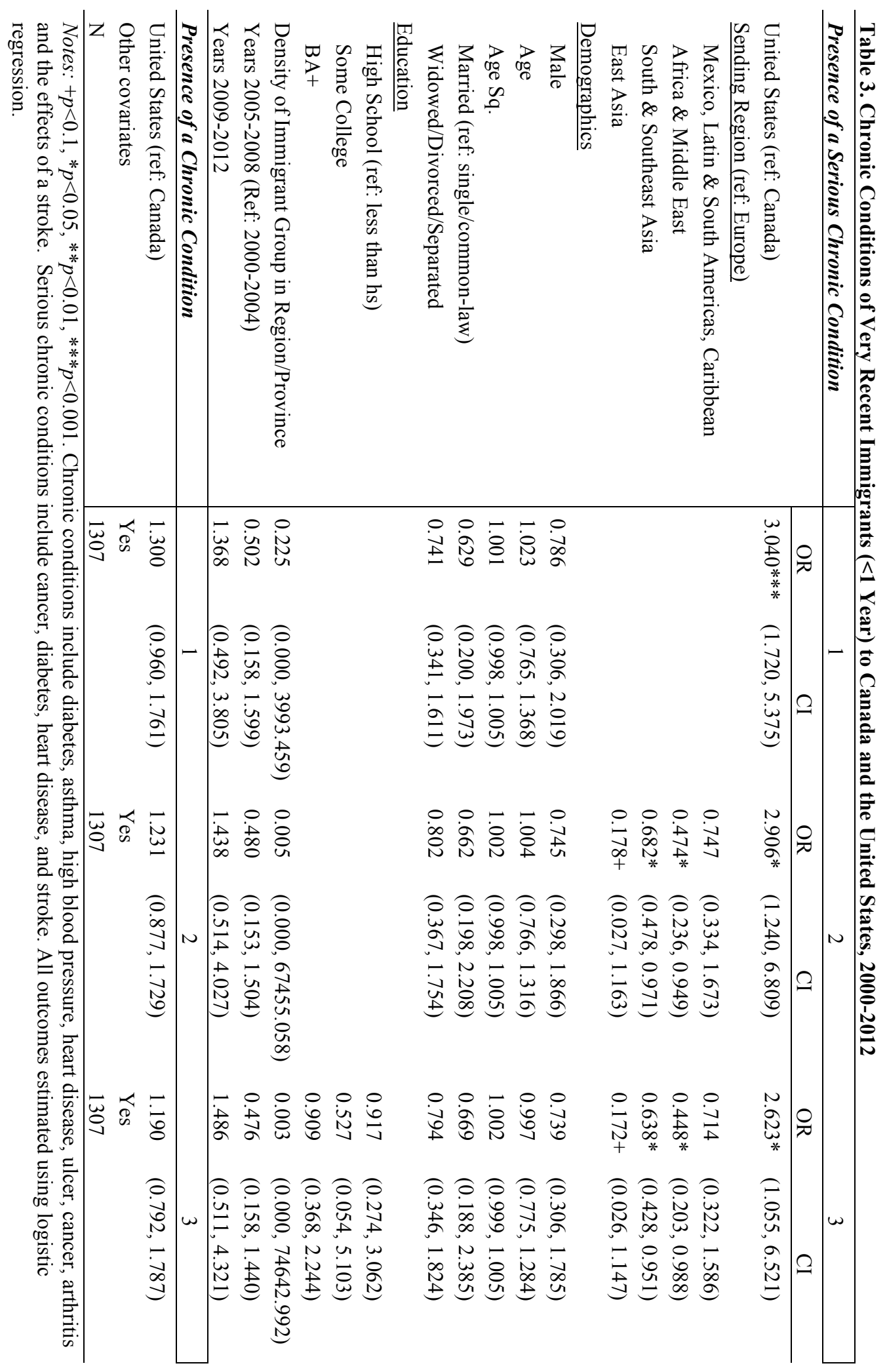


Table 4. Self-Rated Health of New Immigrants to Canada ( $<1.5$ YSI) and the United States ( $<1$ Year), 2000-2012

\begin{tabular}{|c|c|c|c|c|c|c|c|}
\hline & & 1 & & 2 & & 3 & \\
\hline & & OR & $95 \% \mathrm{CI}$ & OR & $95 \% \mathrm{CI}$ & OR & $95 \% \mathrm{CI}$ \\
\hline \multicolumn{8}{|l|}{ Obeseloverweight } \\
\hline United States (ref: Canada) & & $1.623+$ & $(0.976,2.698)$ & $1.250^{*}$ & $(1.036,1.508)$ & 1.149 & $(0.958,1.379)$ \\
\hline \multicolumn{8}{|c|}{ Presence of a Serious Chronic Condition } \\
\hline United States (ref: Canada) & & $2.475 * * *$ & $(1.552,3.947)$ & $2.382 * *$ & $(1.362,4.165)$ & $2.146^{*}$ & $(1.114,4.134)$ \\
\hline \multirow[t]{2}{*}{ United States (ref: Canada) } & & $1.332+$ & $(0.987,1.796)$ & $1.327 *$ & $(1.054,1.673)$ & $1.339+$ & $(1.000,1.793)$ \\
\hline & $\mathrm{N}$ & 2073 & & 2073 & & 2073 & \\
\hline
\end{tabular}

Notes: $+p<0.1,{ }^{*} p<0.05,{ }^{*} p<0.01,{ }^{* * *} p<0.001$. Models include the same set of controls in Table 2 and 3 . 
Table 5. Health of New Immigrants to the United States and Canada ( $<1.5$ Year), Excluding Mexican Immigrants, 2000-2012

\begin{tabular}{llc|lr|l}
\hline & \multicolumn{2}{l|}{ Obese/overweight } & \multicolumn{2}{l|}{$\begin{array}{l}\text { Serious Chronic } \\
\text { Condition }\end{array}$} & \multicolumn{2}{l}{ Chronic Condition } \\
\hline & OR $95 \%$ CI & \multicolumn{2}{l}{ OR $95 \%$ CI } & OR & $95 \%$ CI \\
\hline United States (ref. Canada) & $1.120+\quad(0.894,1.403)$ & $2.450 * \quad(1.057,5.679)$ & 1.362 & $(0.946,1.961)$ \\
\hline $\mathrm{N}$ & 1,644 & & 1,772 & 1,772 \\
\hline
\end{tabular}

Notes: $+p<0.1,{ }^{*} p<0.05, * * p<0.01,{ }^{* * *} p<0.001$. Model 3 presented. Models include the same set of controls as in Table 2 and 3. 


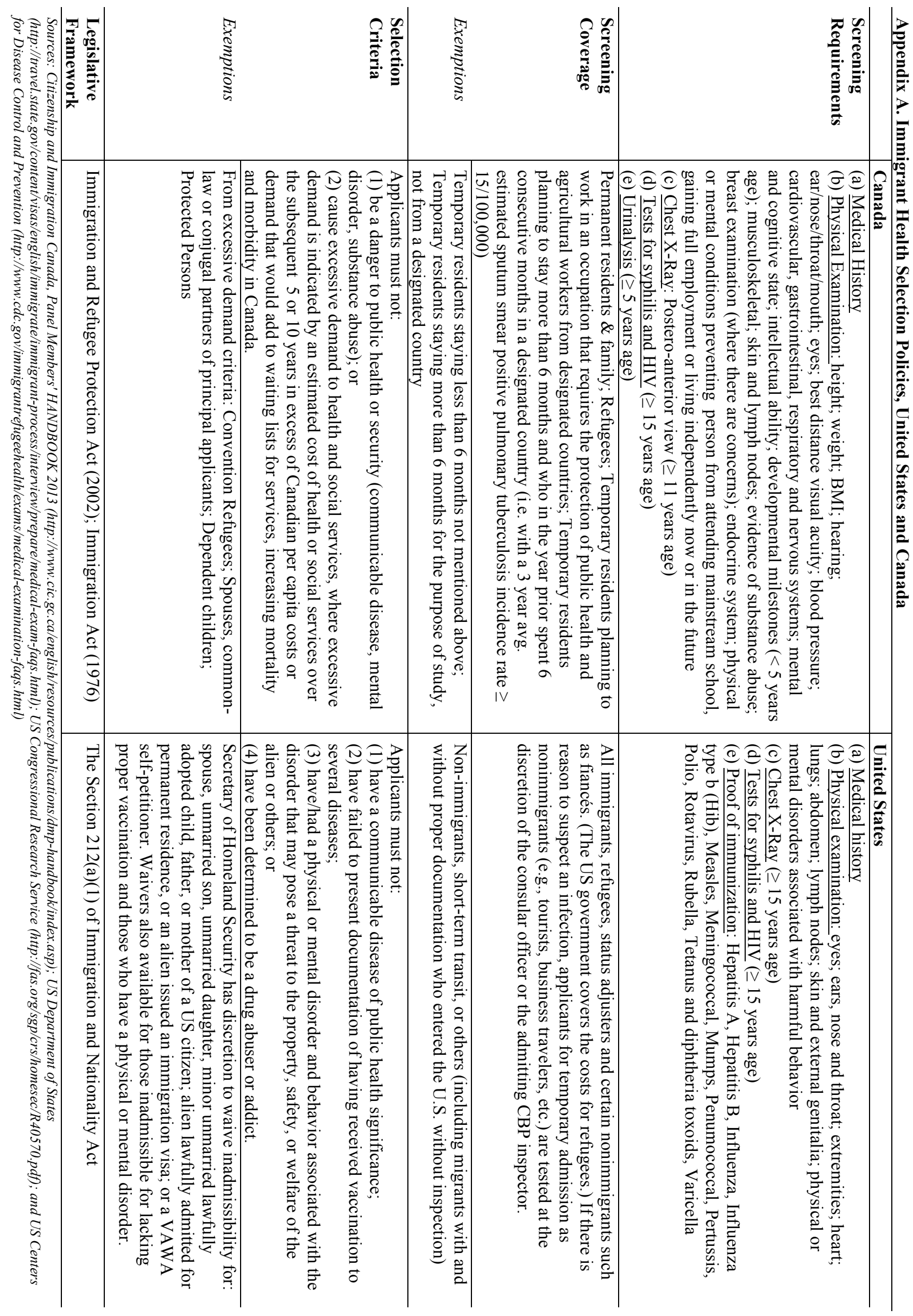


Appendix B. Health of New Immigrants to Canada and the United States ( $<1$ Year) Relative to the Nativeborn Population, 2000-2012

\begin{tabular}{|c|c|c|c|c|c|c|}
\hline & \multicolumn{2}{|c|}{ Obese/overweight } & \multicolumn{2}{|c|}{ Chronic Condition } & \multicolumn{2}{|c|}{$\begin{array}{l}\text { Serious Chronic } \\
\text { Condition }\end{array}$} \\
\hline & OR & $95 \% \mathrm{CI}$ & OR & $95 \% \mathrm{CI}$ & OR & $95 \% \mathrm{CI}$ \\
\hline$\frac{\text { United States }}{\text { New Immigrant (vs. natives) }}$ & 0.454 & $(0.389,0.530)$ & 0.257 & $(0.207,0.318)$ & 0.279 & $(0.180,0.431)$ \\
\hline $\mathrm{N}$ & 199577 & & 206490 & & 206490 & \\
\hline$\frac{\text { Canada }}{\text { New Immigrant (vs. natives) }}$ & 0.483 & $(0.393,0.593)$ & 0.440 & $(0.328,0.590)$ & 0.381 & $(0.169,0.859)$ \\
\hline $\mathrm{N}$ & 330076 & & 341479 & & 341479 & \\
\hline
\end{tabular}

Notes: Models include the same set of controls as in Table 2 and 3. 